\title{
Persistência dos Herbicidas Imazethapyr e Clomazone em LÂMINA DE ÁGUA do ARROZ IRRIGADO ${ }^{1}$
}

\author{
Imazethapyr and Clomazone Persistence in Rice Paddy Water
}

\author{
SANTOS, F.M. ${ }^{2}$, MARCHESAN, E. ${ }^{3}$, MACHADO, S.L.O. ${ }^{4}$, AVILA, L.A. ${ }^{5}$, ZANELLA, $^{6}{ }^{6}$ e \\ GONÇALVES, F.F.?
}

\begin{abstract}
RESUMO - Os herbicidas podem persistir no solo ou ser carreados para fora da área, contaminando mananciais hídricos a jusante da lavoura. Em vista disso, o presente trabalho objetivou estimar a persistência dos herbicidas imazethapyr e clomazone na lâmina de água de arroz irrigado. Para isso, foi realizado um ensaio com diferentes doses e épocas de aplicação da mistura formulada (75 g i.a. ha ${ }^{-1}$ de imazethapyr +25 g i.a. ha-1 de imazapic) e clomazone (1.500 g i.a. ha-1). Para determinação dos produtos na água de irrigação, foram coletadas amostras de água a partir do primeiro dia até 62 dias após a inundação. Os resultados demonstraram que o período de detecção dos herbicidas na água de irrigação foi mais longo para o imazethapyr que para o clomazone. A meia-vida do imazethapyr na lâmina da água variou conforme o tratamento, com valores entre 1,6 e 6,2 dias, e a do clomazone foi de cinco dias.
\end{abstract}

Palavras-chave: imazethapyr, clomazone, residual na água, Oryza sativa.

\begin{abstract}
Herbicides can persist in soil and be transported from the application site to the environment. An experiment was conducted to estimate imazethapyr and clomazone persistence in rice paddy water. The treatments included application of the formulated herbicide mixture (imazethapyr $75 \mathrm{~g}$ a.i. $\mathrm{L}^{-1}+$ imazapic $25 \mathrm{~g}$ a.i. $\mathrm{L}^{-1}$ ) and clomazone $\left(500 \mathrm{~g}\right.$ a.i. $\left.\mathrm{L}^{-1}\right)$. Imazethapyr and clomazone concentrations in water were evaluated from the $1^{\text {st }}$ to the $62^{\text {nd }}$ day after flooding. The period of herbicide detection in water was longer for imazethapyr. Imazethapyr half-life in paddy water varied between 1.6 and 6.2 days and clomazone half-life was 5 days.
\end{abstract}

Keywords: imazethapyr, clomazone, residues in water, Oryza sativa.

\section{INTRODUÇÃO}

A água é um recurso natural renovável de reservas limitadas e demanda crescente. A agricultura demanda grande volume de água, sendo responsável por $69 \%$ da extração anual (FAO, 2003). Além dessa alta demanda, a agricultura ainda oferece riscos de contaminação dos mananciais hídricos superficiais e subterrâneos, devido ao uso de agroquímicos nas lavouras. Nos Estados Unidos, estima-se que de 50 a $60 \%$ da carga poluente de lagos e rios provenha de práticas agrícolas (Gburek \& Sharpley, 1997).

A lavoura de arroz irrigado é um dos sistemas de produção que mais demandam água. No Rio Grande do Sul, são utilizados

1 Recebido para publicação em 23.9.2007 e na forma revisada em 26.4.2008.

Parte integrante da dissertação de mestrado do primeiro autor. Pesquisa financiada pelo CNPq, CAPES, FAPERGS e UFSM.

2 Eng-o -Agr ${ }^{-}$, Mestre em Agronomia pela Universidade Federal de Santa Maria (UFSM), 97105-210, Dep. de Fitotecnia, prédio 44, sala 5335, Santa Maria-RS <fernandoagro18@hotmail.com>; ${ }^{3}$ Engo-Agr ${ }^{\circ}$, Dr., Prof. do Dep. de Fitotecnia da UFSM, <emarch@ccr.ufsm.br>; ${ }^{4}$ Eng $^{-}$-Agr ${ }^{\circ}$, Dr., Prof. do Dep. de Defesa Fitossanitária da UFSM; ${ }^{5}$ Eng - -Agr ${ }^{\circ}$, Ph.D., Prof. do Dep. de Fitotecnia da UFSM; ${ }^{6}$ Químico, Dr., Prof. do Dep. de Química da UFSM; ${ }^{7}$ Químico, doutorando em Química da UFSM. 
anualmente cerca de 1 milhão de hectares para o cultivo do arroz, sendo usados em média 5.374 a $6.422 \mathrm{~m}^{3}$ de água por hectare de arroz, desconsiderando as perdas de água por condução (Machado et al., 2006). Além disso, para assegurar maior produtividade, o uso de agroquímicos tem sido largamente adotado, ocasionando especulações acerca da responsabilidade da lavoura orizícola na contaminação dos mananciais hídricos.

A mistura formulada de imazethapyr e imazapic (75 e 25 g i.a. $\mathrm{L}^{-1}$, respectivamente) é um dos herbicidas mais utilizados na lavoura orizícola gaúcha para controle do arroz-verme1ho. As duas moléculas herbicidas pertencem ao grupo químico das imidazolinonas e são caracterizadas pela eficácia em baixas doses, pelo largo espectro de controle de plantas daninhas e pela longa persistência no solo (Shaw \& Wixson, 1991; Loux \& Reese, 1993). Estudos indicam que a persistência desses herbicidas no solo é influenciada pelo pH (Loux \& Reese, 1992), pela umidade (Baughman \& Shaw, 1996) e pelo teor de matéria orgânica do solo (Stougaard et al., 1990). Os herbicidas do grupo químico das imidazolinonas apresentam como principais mecanismos de dissipação a degradação microbiana (Goetz et al., 1990) e a decomposição fotolítica, especialmente quando expostos à luz ultravioleta (Mallipudi et al., 1991). Tanto o imazethapyr quanto o imazapic sofrem limitada biodegradação sob condições anaeróbicas (Senseman, 2007).

O herbicida clomazone tem sua atividade influenciada pela matéria orgânica e textura (Loux \& Slife, 1989). A meia-vida do clomazone no solo varia de 5 a 117 dias, dependendo do tipo do solo e das condições ambientais (Curran et al., 1992; Kirksey et al., 1996; Mervosh et al., 1995). Senseman (2007) relata que a persistência do clomazone é menor em solos arenosos do que em solos argilosos. A degradação do clomazone é mais rápida em condições anaeróbicas do que em condições aeróbicas (Senseman, 2007); em solo em condições aeróbicas, a meia-vida do herbicida varia de 90 a 276 dias e, em solo anaeróbico, sua meia-vida média é de 60 dias (California, 2003).

Em grande parte das lavouras de arroz, a aplicação dos herbicidas é seguida pela inundação da área e, dependendo do manejo de água adotado e da precipitação pluvial, os herbicidas podem persistir por maior tempo no ambiente e ser transportados para fora da área, contaminando os mananciais hídricos a jusante da lavoura. Por isso, o presente trabalho visou estimar a persistência dos herbicidas imazethapyr e clomazone em lâmina de água da lavoura de arroz irrigado.

\section{MATERIAL E MÉTODOS}

O experimento foi conduzido no ano agrícola 2004/05, na área experimental do Departamento de Fitotecnia da UFSM, em área de várzea, onde não havia histórico da aplicação de imazethapyr e clomazone para controle de plantas daninhas. O solo é classificado como Planossolo Hidromórfico eutrófico arênico, com as seguintes características: $\mathrm{pH}_{\text {água }}(1: 1)=4,5$; $\mathrm{P}=6,9 \mathrm{mg} \mathrm{dm}^{-3} ; \mathrm{K}=55 \mathrm{mg} \mathrm{dm}^{-3} ; \mathrm{MO}=1,2 \%$; $\mathrm{Ca}=2,5 \mathrm{cmol}_{\mathrm{c}} \mathrm{dm}^{-3} ; \mathrm{Mg}=1,3 \mathrm{cmol}_{\mathrm{c}} \mathrm{dm}^{-3}$; $\mathrm{Al}=1,4 \mathrm{cmol}_{\mathrm{c}} \mathrm{dm}^{-3}$; e argila $=17 \%$. O clima é classificado como subtropical úmido, classe 'Cfa'; as temperaturas mínimas, máximas e médias, a insolação e a precipitação verificadas durante o período de ensaio encontramse na Tabela 1.

O delineamento experimental utilizado foi de blocos ao acaso, contendo quatro tratamentos e cinco repetições, com unidades experimentais medindo $5 \times 4 \mathrm{~m}\left(20 \mathrm{~m}^{2}\right)$. Os tratamentos constituíram da aplicação da mistura formulada de imazethapyr e imazapic $\left(75+25\right.$ g i.a. $\left.\mathrm{L}^{-1}\right)$ ou da aplicação de clomazone (Tabela 2). Nos tratamentos 1 a 3 foi expressa somente a concentração de imazethapyr, pois foi o único analisado na água.

O preparo do solo foi realizado no sistema convencional, consistindo em duas gradagens pesadas e três gradagens leves para nivelamento do terreno. O cultivar IRGA $422 \mathrm{CL}$ foi semeado em linhas espaçadas de $0,17 \mathrm{~m}$, em $28 / 10 / 2004$, na densidade de $120 \mathrm{~kg}$ de sementes ha ${ }^{-1}$; a emergência do arroz ocorreu aos 12 dias após a semeadura (DAS). Juntamente com a semeadura do arroz, foi realizada a adubação de base, aplicando-se 7,70 e $105 \mathrm{~kg} \mathrm{ha}^{-1}$ de $\mathrm{N}, \mathrm{P}_{2} \mathrm{O}_{5}$ e $\mathrm{K}_{2} \mathrm{O}$, respectivamente. Para adubação de cobertura, foram utilizados $120 \mathrm{~kg} \mathrm{ha}^{-1} \mathrm{de} \mathrm{N}$ na forma de uréia, aplicandose a metade da dose no início do perfilhamento (V4) e o restante na iniciação da panícula (R0), 
Tabela 1 - Temperaturas mínimas, máximas e médias, insolação e precipitação pluvial, por decêndio, ocorridas durante o período de realização do experimento. Santa Maria-RS, 2006

\begin{tabular}{|c|c|c|c|c|c|c|}
\hline \multirow{2}{*}{ Mês } & \multirow{2}{*}{ Decêndio } & \multicolumn{3}{|c|}{ Temperatura $\left({ }^{\circ} \mathrm{C}\right)$} & \multirow{2}{*}{ Insolação (h) } & \multirow{2}{*}{$\begin{array}{c}\text { Precipitação } \\
(\mathrm{mm})\end{array}$} \\
\hline & & Máxima & Mínima & Média & & \\
\hline \multirow{3}{*}{ 总 } & $01-10$ & 25,5 & 10,9 & 18,2 & 10,1 & 4,4 \\
\hline & $11-20$ & 24,7 & 13,2 & 19,0 & 7,2 & 94,3 \\
\hline & $21-31$ & 26,8 & 12,3 & 19,6 & 8,6 & 21,0 \\
\hline \multirow{3}{*}{$\begin{array}{l}\text { O } \\
\text { है } \\
\text { ह } \\
\text { ż } \\
\text { Z }\end{array}$} & $01-10$ & 25,9 & 14,7 & 20,3 & 5,2 & 123,6 \\
\hline & $11-20$ & 25,7 & 14,9 & 20,3 & 8,5 & 24,1 \\
\hline & $21-30$ & 27,7 & 15,4 & 21,6 & 6,2 & 0,0 \\
\hline \multirow{3}{*}{ 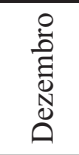 } & $01-10$ & 30,5 & 19,7 & 25,1 & 6,5 & 29,0 \\
\hline & $11-20$ & 30,2 & 16,7 & 23,5 & 9,7 & 32,8 \\
\hline & $21-31$ & 30,5 & 17,0 & 23,7 & 10,7 & 0,4 \\
\hline \multirow{3}{*}{$\begin{array}{l}\stackrel{0}{U} \\
\stackrel{\Xi}{\Xi}\end{array}$} & $01-10$ & 34,9 & 21,8 & 28,3 & 8,0 & 14,1 \\
\hline & $11-20$ & 33,2 & 19,2 & 26,2 & 10,4 & 35,7 \\
\hline & $21-31$ & 32,4 & 18,6 & 25,5 & 8,6 & 0,0 \\
\hline
\end{tabular}

* Dados coletados na Estação Meteorológica da Universidade Federal de Santa Maria/RS/Brasil.

segundo escala de Counce et al. (2000). Juntamente com a segunda aplicação de $\mathrm{N}$ em cobertura, foram utilizados 500 g i.a. ha ${ }^{-1}$ do inseticida carbofuran, para controle de larvas do gorgulho-aquático-do-arroz (Oryzophagus oryzae).

A aplicação do herbicida em PRE foi efetuada aos 2 DAS, utilizando-se pulverizador costal pressurizado com $\mathrm{CO}_{2}$ munido de pontas 11002 do tipo leque, calibrado para aplicar uma vazão de $125 \mathrm{~L} \mathrm{ha}^{-1}$. A aplicação em POS foi efetuada 16 dias após a emergência (DAE), quando a maioria das plantas do arroz cultivado se encontrava no estádio V4, ou seja, com quatro folhas formadas, enquanto as plantas de arrozvermelho se encontravam no estádio V5. Para aplicação em POS, utilizou-se o mesmo pulverizador acima referido, com vazão de $150 \mathrm{~L} \mathrm{ha}^{-1}$ e adição de $0,5 \% \mathrm{v} \mathrm{v}^{-1}$ de óleo mineral emulsionável. A inundação da área foi realizada um dia após a aplicação do tratamento em POS, com lâmina d'água de $10 \mathrm{~cm}$ de altura, aproximadamente. Cada parcela foi separada por taipas, com entrada e saída de água individual, como forma de evitar a contaminação entre os tratamentos, sendo a irrigação mantida durante todo o ciclo da cultura.
Durante o período entre a aplicação dos herbicidas em PRE e a entrada d'água na lavoura ocorreram precipitações, mas a água ficou retida nas parcelas. No entanto, aos 11 dias após a aplicação dos tratamentos em PRE, devido à precipitação de $63 \mathrm{~mm}$, realizou-se coleta d'água, para detecção dos resíduos de herbicidas na água da chuva e posterior drenagem das parcelas. Foram realizadas ainda coletas de água, em cada parcela, no $1^{\circ}, 2^{\circ}, 3^{\circ}, 5^{\circ}$,

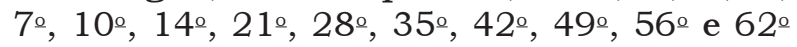
dias após a inundação do ensaio; o período entre a aplicação dos tratamentos em PRE e a entrada de água foi de 26 dias. Depois de coletadas, as amostras foram armazenadas em frasco de vidro âmbar, acidificadas com $\mathrm{H}_{3} \mathrm{PO}_{4}$ 1:1 (v.v. ${ }^{-1}$ ) e, sob refrigeração, transportadas para a análise química no Laboratório de Análise de Resíduos de Pesticidas (LARP) do Departamento de Química da UFSM, para análise conforme metodologia descrita por Zanella et al. (2003).

Alíquota de $250 \mathrm{~mL}$ de amostra foi acidificada e pré-concentrada em cartuchos contendo $200 \mathrm{mg}$ de $\mathrm{C}_{18}$, sendo a eluição executada por duas vezes com $500 \mu \mathrm{L}$ de metanol. A detecção e a quantificação dos herbicidas foram 
realizadas utilizando-se HPLC-UV, a $220 \mathrm{~nm}$, munidas de uma coluna Bondesil $\mathrm{C}_{18}$ $(250 \times 4,6 \mathrm{~mm}$ i.d; $5 \mu \mathrm{m})$, com fase móvel constituída de metanol e água $\left(60: 40 \mathrm{vv}^{-1}\right)$, ajustada a pH 4,0 com ácido fosfórico, com vazão de $0,8 \mathrm{~mL} \mathrm{~min}^{-1}$. O logaritmo natural da concentração restante do imazethapyr $[\ln (\mathrm{C} / \mathrm{Co})]$ foi calculado e, através da plotagem desse valor com o tempo em horas, foi obtida a constante da taxa de dissipação dos herbicidas na água $\left(\mathrm{k}_{\mathrm{p}}\right)$. Os valores da meia-vida dos herbicidas foram calculados usando a equação:

$$
t_{1 / 2}=\frac{\ln (2)}{k_{p}}
$$

sendo $\mathrm{k}_{\mathrm{p}}$ o valor absoluto da inclinação e a taxa de dissipação dos herbicidas na água. As constantes da taxa de dissipação dos herbicidas foram submetidas à análise de variância, sendo as médias comparadas pelo teste de Tukey $(\mathrm{P} \leq 0,05)$.

\section{RESULTADOS E DISCUSSÃO}

A maior persistência de imazethapyr foi observada com a aplicação de $52,5 \mathrm{~g} \mathrm{ha}^{-1}$ de herbicida em PRE, seguido da mesma dose em POS, com niveis detectáveis em água até 27 dias após o estabelecimento da lâmina de água na área (Tabela 2). Resultados similares foram encontrados por Marcolin et al. (2003), que verificaram concentração detectável de imazethapyr na lâmina d'água até os 30 dias após sua aplicação. Já a detecção de clomazone foi observada até os 13 dias após a entrada da água - comportamento similar à aplicação somente em PRE de imazethapyr, na dose de
$75 \mathrm{~g} \mathrm{ha}^{-1}$. Autores como Machado et al. (2003) encontraram persistência de 28 dias do clomazone na lâmina de água.

A concentração dos herbicidas decresceu, tanto para o imazethapyr quanto para o clomazone, em função do tempo (Figura 1A). Esse decréscimo pode ser explicado pela existência de condições climáticas favoráveis à degradação dos herbicidas, como insolação e temperatura (Tabela 1). O clomazone sofre degradação microbiana em solos úmidos e sob altas temperaturas (Colômbia, 2005). Em solo arenoso, a degradação do clomazone é mais rápida, devido à sua disponibilidade na solução do solo. Cumming \& Doyle (2002), avaliando quatro tipos diferentes de solo, encontraram maior persistência do clomazone em solo com maior teor de argila. Teores menores de argila e matéria orgânica também contribuem na dissipação do imazethapyr, pois o torna mais disponivel na solução do solo (Avila, 2005). Segundo esse autor, maior quantidade de água na solução do solo facilita a diluição do herbicida e sua mobilidade, diminuindo, com isso, sua concentração.

Em contrapartida, a baixa sorção do herbicida ao solo (Senseman, 2007) pode ter facilitado sua lixiviação, proporcionando seu transporte para camadas mais profundas, onde a degradação microbiana não é tão eficiente. Estudos indicam que o imazethapyr, em solos não-revolvidos, move-se na coluna do solo até $30 \mathrm{~cm}$ (O'Dell et al., 1992). O imazethapyr é adsorvido em maior quantidade em $\mathrm{pH}$ baixo (Che et al., 1992; Gennari et al., 1998), tornando-se menos móvel e mais persistente no solo (Loux \& Reese, 1993). A sorção tem, portanto,

Tabela 2 - Efeito do tratamento herbicida no período de detecção (PD) dos herbicidas, constante de dissipação (k) e meia-vida dos herbicidas em água $\left(\mathrm{t}_{1 / 2}\right)$, calculados a partir da entrada de água. Santa Maria-RS, 2006

\begin{tabular}{|l|c|c|c|c|}
\hline \multirow{2}{*}{ Tratamento } & \multicolumn{2}{|c|}{ PD } & \multirow{2}{*}{$\begin{array}{c}\mathrm{t}_{1 / 2} \\
(\text { dias })\end{array}$} \\
\cline { 2 - 5 } & DAEA $^{4 /}$ & Total $^{5 /}$ & & 6,2 \\
\hline Imazethapyr $\left(52,5^{1 /} \mathrm{PRE}^{2 /}+52,5 \mathrm{POS}^{3 /}\right)$ & 27 & 53 & $0,1126 \mathrm{~b}$ & 1,6 \\
\hline Imazethapyr $(75,0 \mathrm{PRE})$ & 13 & 39 & $0,4450 \mathrm{a}$ & 5,2 \\
\hline Imazethapyr (75,0 POS) & 20 & 20 & $0,1342 \mathrm{~b}$ & 5,0 \\
\hline Clomazone (1500 PRE) & 13 & 39 & $0,1376 \mathrm{~b}$ & \\
\hline
\end{tabular}

1/ Dose expressa em gramas de ingrediente ativo por hectare; ㄴ/aplicação em pré-emergência; 3 a aplicação em pós-emergência; ${ }^{4 /}$ período em dias após a entrada de água; ${ }^{5 /}$ período total, desde a aplicação do herbicida; ${ }^{6}$ Médias não seguidas pela mesma letra diferem pelo teste de Tukey $\left(\mathrm{p}^{<0,05)}\right.$ 


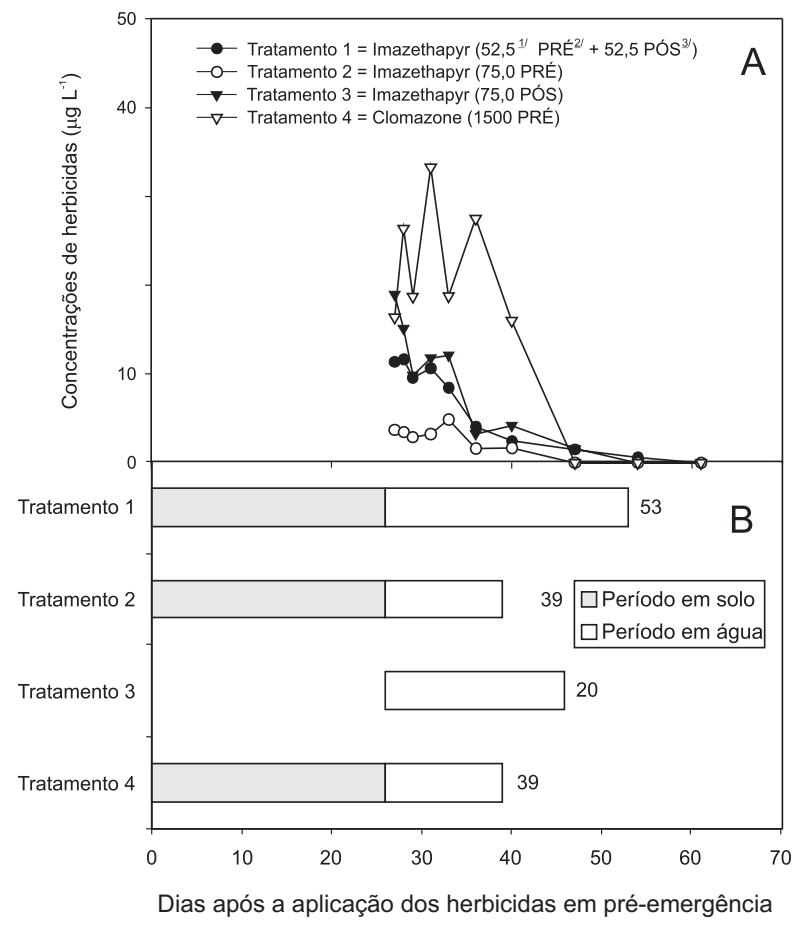

Figura 1 - A: concentração dos herbicidas imazethapyr e clomazone na lâmina de água do arroz irrigado do tratamento herbicida. B: período em que o tratamento herbicida ficou em água e em solo. Santa Maria-RS, 2006. 1/ Dose expressa em gramas de ingrediente ativo por hectare; ${ }^{2} \mathrm{PRE}=$ herbicida aplicado em pré-emergência; ${ }^{3}$ POS = herbicida aplicado em pós-emergência.

impacto na distribuição, biodisponibilidade e persistência de herbicidas no ambiente.

Para o clomazone, a volatilidade é outro fator que contribui em sua dissipação. Além de possuir elevada pressão de vapor, o que proporciona alta volatilidade, a umidade do solo, decorrente da irrigação, pode ter acelerado as perdas do herbicida por volatilização. Thelen et al. (1988) verificaram perdas de clomazone por volatilização com o aumento da umidade do solo. Resultados semelhantes foram encontrados por Cumming \& Doyle (2002), que citam as perdas por vapor em local de elevada umidade no solo.

Os fatores anteriormente expostos (precipitações, características do solo e propriedades físico-químicas dos herbicidas) podem ter ocasionado a redução da concentração do imazethapyr e do clomazone encontrada na coleta realizada logo após a entrada d'água no experimento, que ocorreu 26 dias após a aplicação dos herbicidas em PRE. Com a inundação da área, outros fatores influenciaram a degradação dos herbicidas, como hidrólise e degradação anaeróbica, até estes alcançarem sua concentração mínima detectável na água (Tabela 2). $\mathrm{O}$ herbicida que apresentou maior meia-vida na água foi o clomazone. Estudos demonstram que, dissolvido em água, tal herbicida não degrada facilmente sob a luz, apresentando meia-vida de 30 dias (Califórnia, 2003). Logo, a decomposição do clomazone na água pode ser explicada pelo fato de o herbicida ser rapidamente degradado em condições anaeróbicas. O Departamento de Pesticidas da Califórnia (2003) relata elevada persistência do clomazone no solo sob condições aeróbicas; contudo, sob condições anaeróbicas, a degradação do clomazone é acelerada.

Quanto ao herbicida imazethapyr, sua aplicação em PRE apresentou a maior meiavida entre as doses e épocas de sua aplicação. Para o imazethapyr, a fotólise é um dos principais mecanismos de sua dissipação em condições anaeróbicas, já que a degradação microbiana do herbicida, nessas condições, é quase insignificante (Senseman, 2007). A fotólise, por sua vez, é mais eficiente sob intensa insolação - condição satisfeita no período de detecção do herbicida na lâmina de água - devido à ocorrência de poucas precipitações (Tabela 1). Logo, a menor meiavida do imazethapyr na aplicação somente em POS pode ter decorrido do fato de o herbicida ter tido menor tempo para reações com o solo antes da entrada d'água, o que diminui a adsorção dele ao solo, facilitando sua fotodecomposição em água. Avila (2005) afirma ainda que, quando aplicado em PRE, o herbicida dispõe de mais tempo para a sorção ao solo, diminuindo sua disponibilidade na solução do solo. Assim, segundo o autor, a adsorção ao solo pode afetar a fotodecomposição do imazethapyr aplicado em PRE. Em contrapartida, há suposição de que, após algumas semanas de alagamento, essas reações do herbicida com o solo possam ser desfeitas, em função da elevação do $\mathrm{pH}$ a próximo da neutralidade (Snyder \& Slaton, 2002), o que disponibilizaria aos poucos as moléculas do herbicida na lâmina d'água. Essa mudança no pH, sob inundação da área, pode ocorrer semanas após a entrada d'água, dependendo do tipo do solo, do nivel da matéria orgânica, da população de 
microrganismos, de temperatura e de outras propriedades químicas do solo (Snyder \& Slaton, 2002).

A meia-vida do imazethapyr na lâmina d'água variou conforme o tratamento, com valores entre 1,6 e 6,2 dias, e a do clomazone foi de cinco dias. Contudo, essa meia-vida referese à sua dissipação em água, e em solo a meiavida pode ser maior. Além do período de 27 e 13 dias de detecção na lâmina de água de irrigação para imazethapyr e clomazone, respectivamente, cabe ressaltar ainda que os herbicidas persistiram por 26 dias no solo, durante o período entre sua aplicação em PRE e a entrada da lâmina d'água na lavoura, totalizando um período de 53 e 39 dias, respectivamente para imazethapyr e clomazone. Nesse período, esses herbicidas podem, potencialmente, ser transportados da lavoura para fora do sistema produtivo, recomendando-se a adoção de práticas de manejo que reduzam essa possibilidade.

\section{AGRADECIMENTOS}

Os autores agradecem ao Conselho Nacional de Desenvolvimento Científico e Tecnológico (CNPq), pelo auxílio financeiro advindo da concessão de bolsas de mestrado, pesquisa e iniciação científica, e à Universidade Federal de Santa Maria, pela viabilização das pesquisas realizadas.

\section{LITERATURA CITADA}

AVILA, L. A. Imazethapyr: Red rice control and resistance, and environmental fate. 2005. $81 \mathrm{f}$. Dissertation (Ph.D.) Graduate Studies of Texas A\&M University, Stanford, 2005.

BAUGHMAN, T. A; SHAW, D. R. Effect of wetting/drying cycles on dissipation patterns of bioavailable imazaquin. Weed Sci., v. 44, n. 2, p. 380-382, 1996.

CALIFORNIA. Department of Pesticide Regulation. Clomazone. Public Report, 2003 - 01. Disponível em: http://www.cdpr.ca.gov/docs/registration/ ais/publicreports/ 3537.pdf. Acesso em: 11 de maio de 2007

CHE, M. et al. Effect of $\mathrm{pH}$ on sorption and desorption of imazaquin and imazethapyr on clays and humic acid. J. Environ. Qual., v. 21, n. 4, p. 698-703, 1992.

Planta Daninha, Viçosa-MG, v. 26, n. 4, p. 875-881, 2008
COLOMBIA. Ministério de Ambiente, Vivienda y Desarrolo Territorial. República de Colombia. Resolução no $\mathbf{6 8 1}$, de 2 de junho de 2005. "Por la cual se expide um dictamen técnico ambiental para el producto Saat Minuetto ${ }^{\circledR} 480$ EC del ingrediente activo clomazone dentro del trámite administrativo de registro". Colombia: 2005.

COUNCE, P. A.; KEISLING, T. C.; MITCHELL, A. J. A uniform, objective, and adaptive system for expressing rice development. Crop Sci., v. 40, n. 2, p. 436-443, 2000.

CUMMING, J. P.; DOYLE, R. B. Clomazone dissipation in four Tasmanian topsoils. Weed Sci., v. 50, n. 3, p. 405-409, 2002.

CURRAN, W. S.; LIEBL, R. A.; SIMMONS, F. W. Effects of tillage and application methods on clomazone, imazaquin, and imazethapyr persistence. Weed Sci., v. 40, p. 482-489, 1992.

FAO. Faostat database results. 2003. Disponível em: www.fao.org/faostat. Acesso em: abril de 2007.

GBUREK, W. J.; SHARPLEY, A. N. Hydrologic controls on phosphorus loss from upland agricultural watersheds. J. Environ. Qual., n. 27, p. 267-277, 1997

GENNARI, M.; NÉGRE, M.; VIDROLA, D. Adsorption of the herbicides imazapyr, imazethapyr and imazaquin on soils and humic acids. J. Environ. Sci. Health, v. 33, n. 5, p. $547-567,1998$.

GOETZ, A.; LAVY, T.; GBUR, E. Degradation and field persistence of imazethapyr. Weed Sci., v. 38, n. 2, p. 421428, 1990.

KIRKSEY, K. B. et al. Clomazone dissipation in two Tennessee soils. Weed Sci., v. 44, n. 4, p. 959-963, 1996

LOUX, M. M.; REESE, K. D. Effect of soil type and pH on persistence and carryover of imidazolinone herbicides. Weed Technol., v. 7, n. 2, p. 452-458, 1993.

LOUX, M. M.; SLIFE, F. W. Availability and persistence of imazaquin, imazethapyr, and clomazone in soil. Weed Sci., v. 37, n. 2 , p. $259-267,1989$.

LOUX, M.M.; REESE, K.D. Effect of soil pH on adsorption and persistence of imazaquin. Weed Sci., v. 40, n. 3, p. 490-496, 1992.

MACHADO, S. L. O. et al. Consumo de água e perdas de nutrientes e de sedimentos na água de drenagem inicial do arroz irrigado. Ci. Rural, v. 36, n. 1, p. 65-71, 2006.

MACHADO, S. L. O. et al. Persistência de herbicidas na água de irrigação no arroz irrigado. In: CONGRESSO BRASILEIRO DE ARROZ IRRIGADO, 3.; REUNIÃO DA CULTURA DO ARROZ IRRIGADO, 25., 2003, Balneário Camboriú. Anais... Camboriú: EPAGRI, 200 p. 92-694. 
MALLIPUDI, N. M. et al. Photolysis of imazapyr (AC 243997) herbicide in aqueous media. J. Agric. Food Chem., v. 39, n. 2 , p. $412-417,1991$.

MARCOLIN, E.; MACEDO, V. R. M.; GENRO JUNIOR, S. A. Persistência do herbicida imazethapyr na lâmina de água em três sistemas de cultivo de arroz irrigado. In: CONGRESSO BRASILEIRO DE ARROZ IRRIGADO, 3 ., REUNIÃO DA CULTURA DO ARROZ IRRIGADO, 25. Balneário Camboriú, SC. Anais... Camboriú: Epagri, 2003. p. $686-688$

MERVOSH, T. L.; SIMMS, G. K.; STOLLER, E. W. Clomazone fate as affected by microbial activity, temperature, and soil moisture. J. Agric. Food Chem., v. 43, p. $537-543,1995$.

O’DELL, J. D.; WOLT, J. D.; JARDINE, P. M. Transport of imazethapyr in undisturbed soil columns. Soil Sci. Soc. Am. J., v. 56, p. 1711-1715, 1992.
SENSEMAN, S. A. (Ed.). Herbicide handbook. 9.ed. Lawrence: Weed Science Society of America, 2007. 458 p.

SHAW, D.; WIXSON, M. Post emergence combinations of imazaquin or imazethapyr with AC 263,222 for weed control in soybean (Glycine max). Weed Sci., v. 39, p. 644649, 1991.

SNYDER, C. S.; SLATON, D. N. Effects of soil flooding and drying on phosphorus reactions. News Views, p. 1-3, 2002.

STOUGAARD, R. N.; SHEA, P. J.; MARTIN, A. R. Effect of soil type and $\mathrm{pH}$ on adsorption, mobility and efficacy of imazaquin and imazethapyr. Weed Sci., v. 36, n. 1, p. 67-73, 1990.

THELEN, K. D.; KELLS, J. J.; PENNER, D. Comparison of application methods and tillage practices on volatilization of clomazone. Weed Technol., v. 2, p. 323-326, 1988.

ZANELLA, R. et al. Development and validation of a highperformance liquid chromatographic procedure for the determination of herbicide residues in surface and agriculture waters. J. Sep. Sci., v. 26, n. 9/10, p. 935-938, 2003. 